\title{
Sistem Informasi Inventori Pada CV.Tri Manunggal Berbasis Website
}

\author{
Ni Putu Eka Wirayanti ${ }^{1}$, Putu Sugiartawan ${ }^{* 2}$, I Wayan Dharma Suryawan ${ }^{3}$ \\ 1,2,3 Teknik Informatika, STMIK STIKOM Indonesia, Bali, Indonesia \\ e-mail: ${ }^{1}$ eka.wirayanti@ stiki-indonesia.ac.id, *²putu.sugiartawan@stiki-indonesia.ac.id, \\ wayan.dharma@stiki-indonesia.ac.id
}

\begin{abstract}
Abstrak
Abstrak CV. Tri Manunggal merupakan perusahaan yang bergerak pada bidang jasa kontruksi di Bali. Dalam pencatatannya, bagian gudang mengumpulkan dokumen barang persediaan masuk perperiode dikurang dengan persediaan barang keluar, sehingga pada perusahaan CV. Tri Manunggal muncul kendala-kendala yaitu adanya kesalahan perhitungan dalam pencatatan persediaan karena sebelumnya CV. Tri Manunggal masih melakukan pencatatan manual di buku lalu setelah itu disalin ke software Microsoft Excel untuk di print. Berdasarkan latar belakang yang diuraikan diatas, penulis telah merumuskan permasalahan yaitu "bagaimana merancang sistem informasi stok barang gudang berbasis web pada Perusahaan. Adapun tujuan pencatatan stok barang, sehingga mempermudah dan mempercepat pihak perusahaan untuk mendapatkan informasi yang dibutuhkan dalam pencatatan stok barang setiap bulannya. Sistem informasi ini tentu menjamin sebuah pencatatan stok barang dengan terstruktur sesuai input dan output barang. Dari pembahasan mengenai sistem informasi inventori pada $C V$. Tri Manunggal berbasis web tentunya membantu staf di kantor perusahaan khususnya dalam pencatatan stok barang supaya lebih mudah dan efisien. Dapat diketahui bahwa sistem inventori ini merujuk kepada sistem pencatatan otomatis yang dilakukan oleh pengguna atau admin dalam memanajemenkan data.
\end{abstract}

Kata kunci-Sistem Informasi, Inventori, Website, RPL

Abstract
SMKN 1 Ende has a library as one of the facilities provided by the school to support student learning activities. The existence of a library is very important in increasing knowledge for students in schools. However, based on the results of an interview conducted with one of the librarians of SMKN 1 Ende, currently, school library data management is still using manual methods such as recording visitor member data, book data, borrowing data, and returning books in the ledger. As a result, it is inefficient and has a very big risk of mistakenly recording data on borrowing and returning books and other problems that often occur, namely when searching for data on borrowing and returning books where librarians have to reopen existing files so that it takes time. long enough. To overcome the existing problems, it is necessary to make a school library information system that will be tailored to the needs of the library. Based on the description of the problems in the library of SMKN 1 Ende, the theme that will be discussed by the researcher is "Library Information System at SMKN 1 Ende is Website Based". With this system, it can help the data management process by library officers in carrying out their duties such as collecting data on library visitor members, data collection of books, data collection of borrowing transactions, and returning books so that officers complete their duties quickly.

Keywords—Information System,Inventory, Website, RPL

Received Februari $1^{\text {st }}, 2020$; Revised Februari 25 ${ }^{\text {th }}, 2020$; Accepted Maret $10^{\text {th }}, 2020$ 


\section{PENDAHULUAN}

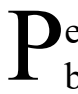
erkembangan teknologi yang sangat pesat di era globalisasi saat ini telah memberikan banyak manfaat dalam kemajuan diberbagai aspek sosial [1]. Teknologi informasi merupakan sarana yang sangat diperlukan dan penting bagi suatu perusahaan. Secara umum teknologi informasi adalah suatu teknologi yang digunakan untuk mengolah data, termasuk memproses, mendapatkan, menyusun, menyimpan, memanipulasi data dalam berbagai cara untuk menghasilkan informasi yang berkualitas, yaitu informasi yang relevan, akurat dan tepat waktu, yang digunakan untuk keperluan pribadi, bisnis, dan pemerintahan dan merupakan informasi yang strategis untuk pengambilan keputusan [2]. Teknologi informasi diharapkan mempermudah pekerjaan agar tujuan perusahaan dapat tercapai secara maksimal, efisien, dan efektif. Beberapa perusahaan memiliki cara tersendiri untuk memajukan perusahaannya, namun masih ada perusahaan yang menggunakan teknik manual dalam berbagai aktivitas kegiatan di perusahaan. Secara tidak sadar, perusahaan belum mengikuti arus teknologi informasi untuk mempermudah aktivitas perusahaan. Dengan bantuan teknologi informasi tentunya membantu perusahaan dalam menangani masalah. CV. Tri Manunggal merupakan perusahaan yang bergerak pada bidang jasa kontruksi di Bali. Perusahaan ini berdiri sejak tahun 2007 yang berlokasi di jl. Gatot Subroto IV Blok III No. 11A Denpasar-Bali.

Berdasarkan hasil wawancara, dalam pencatatannya, bagian gudang mengumpulkan dokumen barang persediaan masuk perperiode dikurang dengan persediaan barang keluar, sehingga pada perusahaan CV. Tri Manunggal muncul kendala-kendala yaitu adanya kesalahan perhitungan dalam pencatatan persediaan karena sebelumnya CV. Tri Manunggal masih melakukan pencatatan manual di buku lalu setelah itu disalin ke software Microsoft Excel untuk di print. Untuk menangani masalah dengan melihat kelemahan yang terdapat pada CV. Tri Manunggal, maka penulis ingin merancang sebuah sistem informasi berbasis web mengenai stok barang di Gudang atau sistem inventori agar meminimalisir terjadinya kesalahan pencatatan stok barang agar lebih terstruktur.

\section{METODE PENELITIAN}

Metode penelitian meliputi analisa permasalahan, arsitektur atau rancangan metode yang digunakan untuk menyelesaikan masalah pada inventory perusahaan.

\subsection{Pengertian Sistem}

Pengertian Sistem menurut Goerge M Scott yaitu "Rancangan sistem menentukan bagaimana suatu sistem dapat menyelesaikan apa yang harus diselesaikan, tahap ini berkaitan mengkonfigurasi dari elemen perangkat lunak serta perangkat keras dari sebuah sistem sehingga penginstalan dari sistem akan memuaskan rancangan yang telah ditetapkan dari pada tahap akhir analisis sistem"[3].

\subsubsection{Karakteristik Sistem}

Menurut [3] "berikut adalah karakteristik sistem yang bisa membedakan suatu sistem dengan sistem lainnya: yang bisa membedakan suatu sistem dengan sistem lainnya:

1. Komponen Sistem (Components), sebuah sistem terdiri dari sejumlah elemen yang saling berinteraksi yakni saling bekerja sama membentuk satu kesatuan. Komponen- komponen sistem atau elemen-elemen dapat berupa satu subsistem atau bagian dari sistem.

2. Batas Sistem (boundary), batas sistem adalah daerah yang membatasi antara sistem dengan lingkungan luarnya. Batas sistem ini kemungkinan suatu sistem dilihat sebagai satu kesatuan. Batas suatu sistem memperlihatkan ruang (scope) dari sistem tersebut. 
3. Lingkungan Luar Sistem (environment), lingkungan luar sistem merupakan semua di luar batas dari suatu sistem yang mempengaruhi operasi sistem. Lingkungan luar sistem bisabersifat menguntungkan bisa juga bersifat merugikan sistem tersebut.

4. Penghubung (interface), penghubung ialah media penghubung diantara satu subsistem dengan subsistem yang lainnya. Melalui penghubung ini memungkinkan sumber-sumber daya mengatur dari satu subsistem ke subsistem yang lainnya. Keluaran (output) dari suatu subsistem akan menjadi masukan (input) sebagai subsistem lainnya melalui penghubung. Dengan penghubung satu subsistem bisa berintegrasi dengan satu subsistem lainnya membentuk satu kesatuan.

5. Masukan (input), masukan merupakan energi yang dimasukkan ke dalam sistem, masukan sistem bisa dalam bentuk masukan perawatan dan masukan sinyal. Masukan perawatan merupakan energi yang dimasukkan agar sistem itu bisa beroperasi guna mendapat keluaran.

6. Keluaran (output), keluaran adalah hasil energi yang diolah serta diklasifikasikan menjadi keluaran yang berguna dari sisa pembuangan.

7. Pengolahan (process), suatu sistem dapat berupa memiliki satu bagian pengolahan atau sistem itu sendiri sebagai pengolahannya. Pengolahan akan merubah masukan menjadi keluaran. Sasaran (objective) atau tujuan (goal), suatu sistem mesti memiliki tujuan (goal) atau sasaran (objective), sasaran dari sistem sangat menentukan hasil masukan yang dibutuhkan sistem serta keluaran yang dihasilkan sistem."

\subsubsection{Informasi}

Informasi merupakan sesuatu yang penting bagi manajemenuntuk mengambil keputusan [4]. Pengertian Informasi yaitu data yang berupa fakta, angka, suara, gambar, simbol kemudian diolah menjadi bentuk yang lebih berguna dan berarti bagi yang menerima informasi [5]. Informasi adalah suatu data yang telah diklasifikasikan atau diolah atau diinterpretasikan untuk digunakan dalam proses pengambilan keputusan [6].

Sistem informasi adalah sebuah sistem yang terdapat dalam organisasi yang mempertemukan kebutuhan pengolahan transaksi harian, mendukung operasi, bersifat manajerial, aktivitas strategis dari suatu organisasi serta menyediakan pihak luar tertentu dengan laporan yang dibutuhkan. Selain pengertian tersebut, sistem informasi adalah suatu komponen dari subsistem yang berikatan dan saling bekerja samauntuk mencapai tujuan yang meliputi pengolahan data menjadi sebuah informasi [3].

\subsubsection{Pengertian Inventori}

Persediaan (inventory) adalah suatu sistem yang menentukan keseimbangan antara investasi penyimpanan persediaan barang. Bisa dikatakan bahwa persediaan barang merupakan aktiva lancar yang meliputi barang-barang milik perusahaan agar dijual dalam satu periode usaha normal [4]. Sistem inventory adalah sekumpulan kebijakan dan pengendalian, yang memonitor tingkat inventory, dan menentukan tingkat mana yang harus dijaga, bila stok harus diisi kembali dan berapa banyak yang harus dipesan [7].

\subsection{Sistem yang sedang berjalan}

Jika Saat ini pada pencatatan data pemesanan barang di CV. Tri Manunggal masih menggunakan Microsoft Excel seperti dalam melakukan pencatatan dan pemesanan. Berikut adalah tahapan-tahapan Aliran sistem yang berjalan di CV. Tri Manunggal sebagai berikut :

Bagian Stok membuat daftar barang habis dan form pengajuan barang habis lalu diberikan kepada admin sehingga data barang habis tersebut diarsipkan. Laporan data barang habis akan diberikan ke pihak supplier. Supplier mencetak nota pembayaran lalu diberikan ke bagian admin dan melakukan pembayaran, sehingga bukti pembayaran diberikan ke supplier.

JSIKTI Vol. 2, No. 3, Maret 2020: $14-25$ 
Supplier akan mengirimkan barang ke bagian gudang. Untuk memperjelas aliran sistem informasi yang ada maka dapat dilihat pada Gambar 1.

\subsubsection{Sistem Yang di Usulkan}

Dikarenakan adanya berbagai permasalahan yang terdapatpada sistem yang sedang berjalan saat ini. Penelitian ini mengusulkan untuk memberikan solusi dalam pemecahan masalah yang sedang dihadapi perusahaan saat ini yaitu mengganti sistem yang sedang berjalan saat ini dengan menggunakan sistem yang baru.

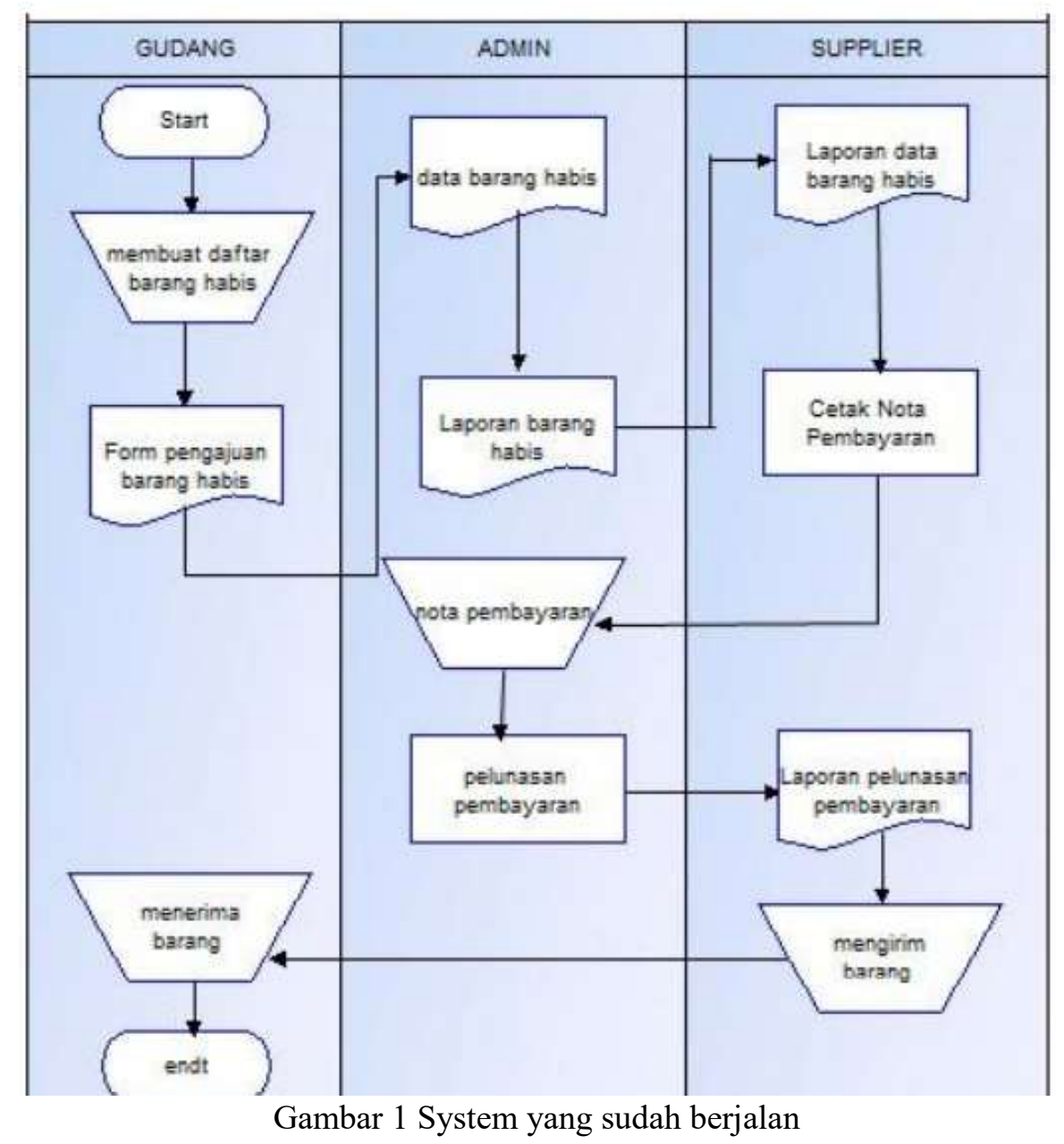

Sehingga proses stok barang dapat dilakukan dalam waktu yang lebih efektif dan efisien. 


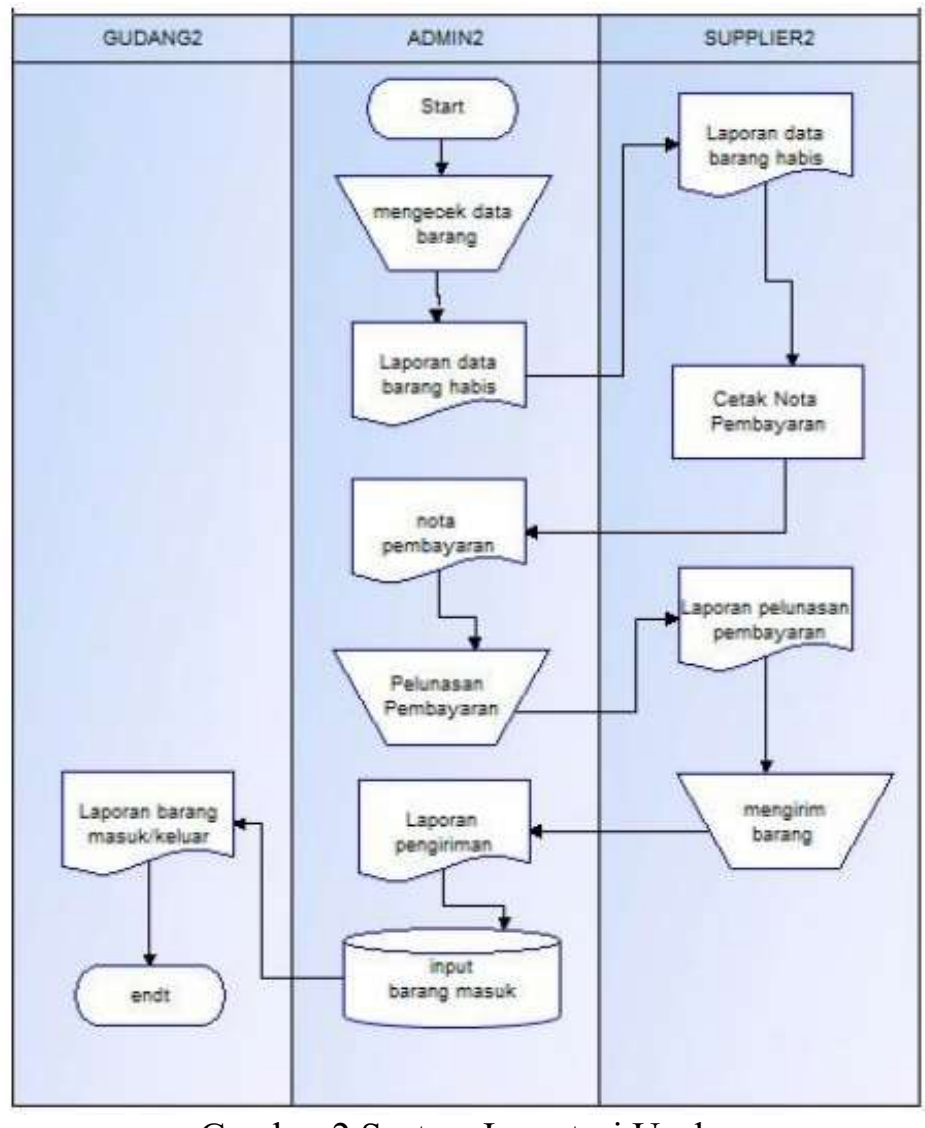

Gambar 2 System Inventori Usulan

Aliran sistem baru yang diusulkan sebagai berikut Admin menerima data barang keluar dan masuk. Admin juga menginput pada sistem, untuk melakukan cek stok. Admin membuat data barang habis untuk dilaporkan ke supplier. Supplier akan mencetak nota pembayaran untuk diberikan ke admin. Lalu admin akan melakukan pembayaranke supplier dan memberikan laporan pelunasan barang. Supplier melakukan pengiriman barang ke admin dan setelah admin mendapatkan laporan barang masuk, admin menginput barang yang masuk ke dalam database. Laporan barang akan diberikan ke pihak gudang. Untuk memperjelas aliran sistem informasi yang ada maka dapat dilihat pada Gambar 2.

\subsubsection{Statement Of Purpose (SOP)}

Sistem informasi stok barang ini mampu melakukan pengolahan data persediaan barang, pengolahan barang masuk dan melihat sisa barang keluar. Adapun perancangan sistem informasi dijabarkan dengan menggunakan Event list, Data Flow Diagram yang meliputi Context Diagram, Data Flow Diagram Level 0, Data Flow Diagram Level 1, Conceptual Data Model dan Physical Data Model. 


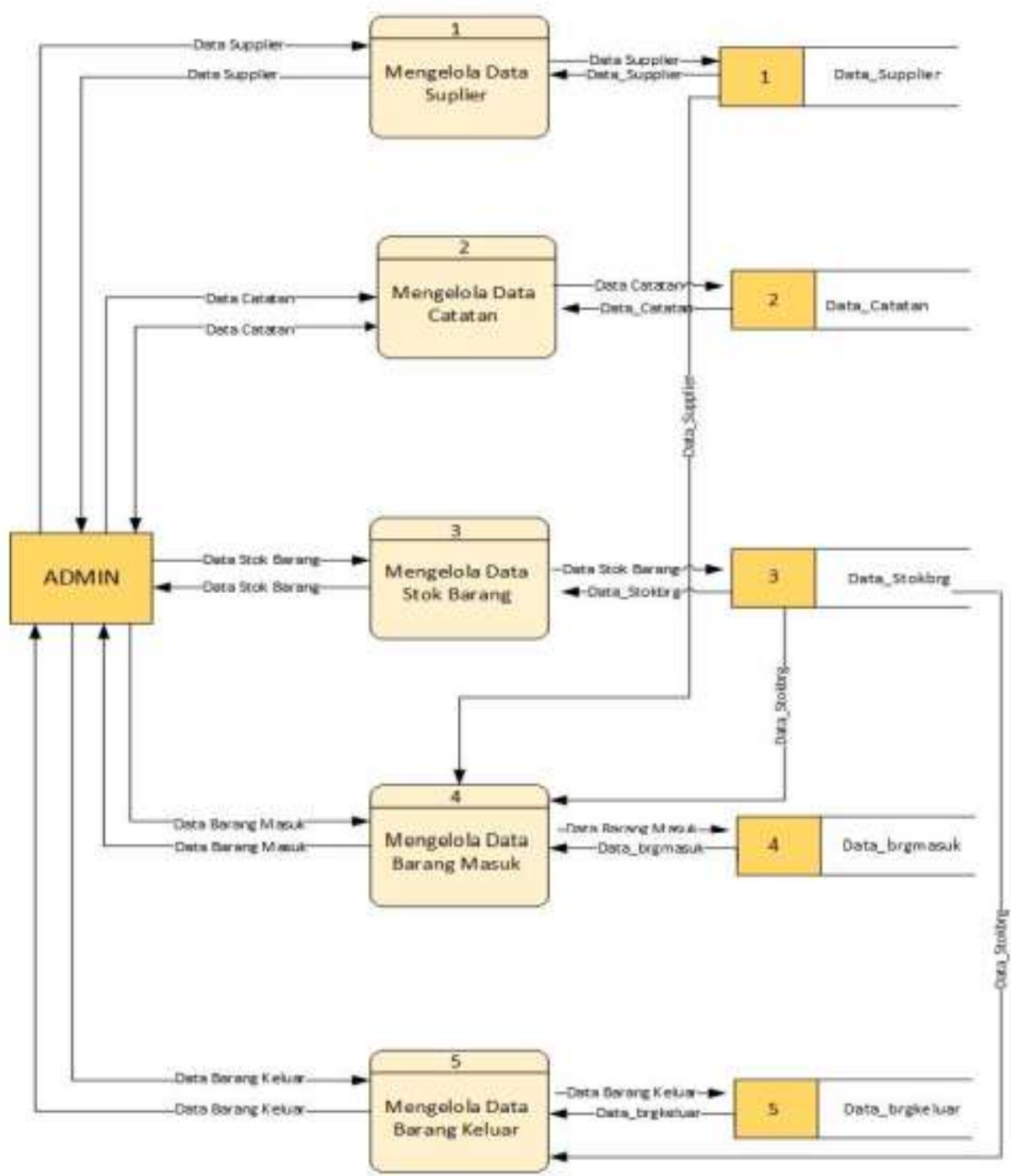

Gambar 3 Data Flow Diagram Level 0

Berdasarkan hasil observasi, wawancara, dan analisa sistem yang sudah dilakukan, berikut adalah daftar kejadian yang akan dibuat dalam sistem informasi stok barang:

1. Data Supplier

2. Kelola data catatan

3. Kelola data stok barang

4. Kelola data barang masuk

5. Kelola data barang keluar

Gambar 3 menjelaskan tentang proses umum yang dapat dilakukan pada sistem informasi stok barang di CV. Tri Manunggal. Pada tahap awal dimulai dengan proses pengolahan data stok barang. Admin dapat melakukan penginputan stok barang terlebih dahulu, lalu diikuti dengan menginput data barang masuk dan data barang keluar. Sehingga admin akan melihat hasil output di tampilan data stok barang. Data flow diagram (DFD) adalah alat yang dapat digunakan untuk menggambarkan sistem yang dirancang [8]. Gambar 3 Data Flow Diagram Level 0 Jika admin ingin mengubah data menjadi format kedalam bentuk .pdf,.xlsx, .csv dan ingin print out, maka admin bisa 
mengeksport data pada fitur Ekspor di menu stok barang, barang masuk dan barang keluar.

Conceptual Data Model (CDM) merupakan model yang merepresentasikan tabel yang merupakan entitas yang berisi atribut. Setiap entitas memiliki satu primary key yang bersifat unik (nilainya tidak sama dengan nilai yang lainnya) dan setiap entitas berhubungan dengan entitas lain yang disebut relationships [9]. Kardinalitas antar tabel dapat dilihat pada Gambar 4 berikut ini.

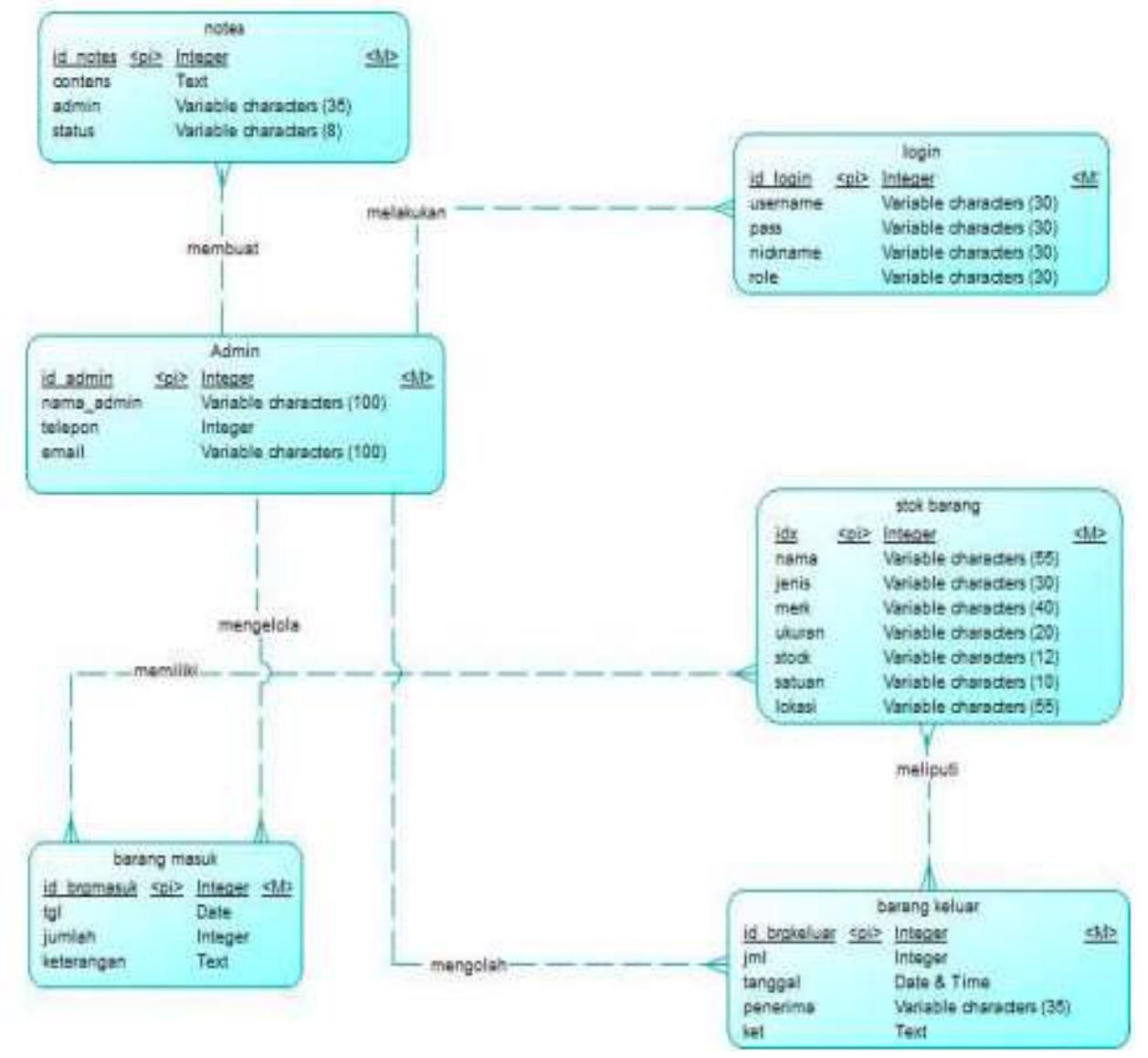

Gambar 4 CDM inventori perusahaan

Physical Data Model menggunakan sejumlah tabel untuk menggambarkan data serta hubungan antara data-data tersebut. Physical Data Model (PDM) adalah suatu jenis model data yang menggambarkan hubungan antar tabel secara fisikal. PDM merupakan hasil generate dari CDM [10]. Untuk lebih jelasnya, dapat dilihat Gambar 5. 


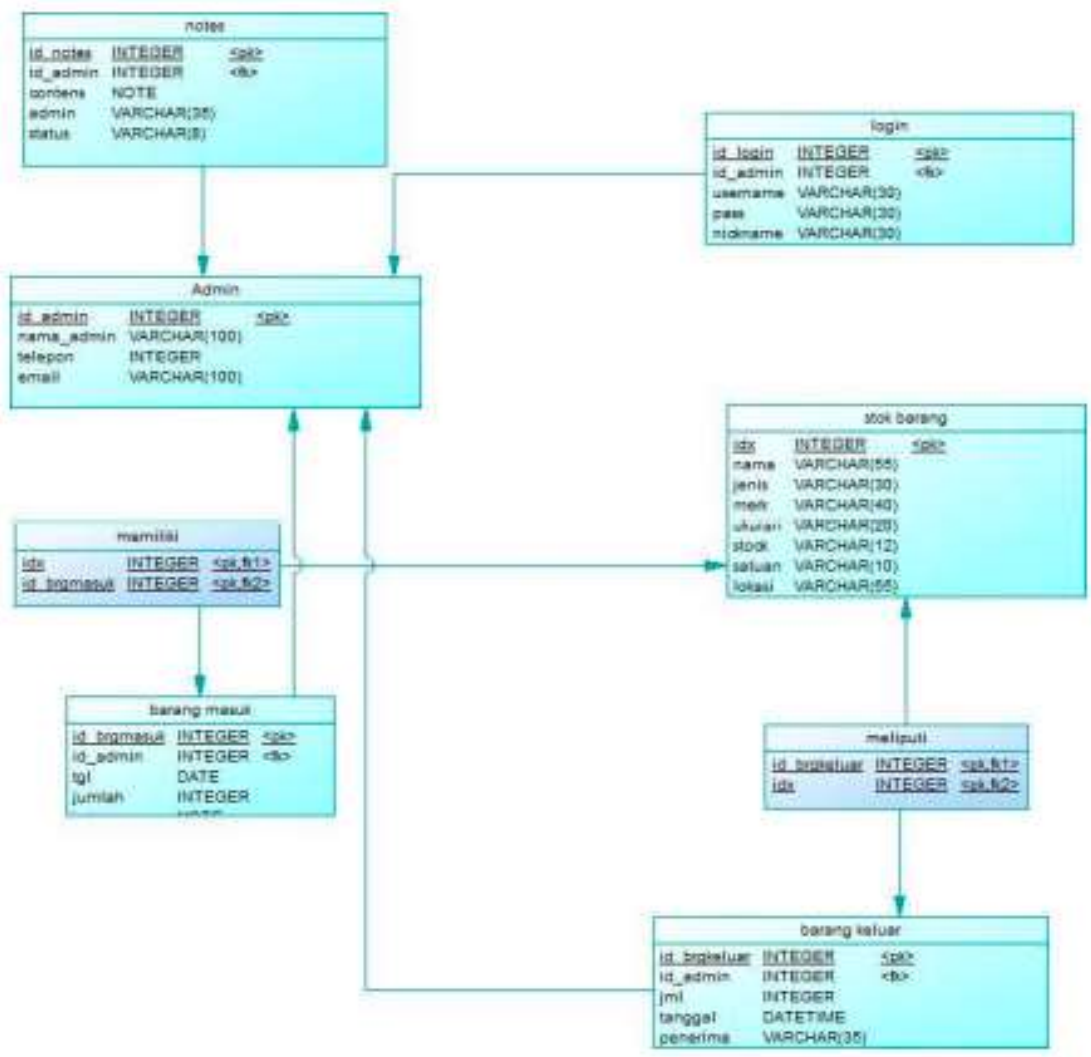

Gambar 5 PDM inventori perusahaan

\section{HASIL DAN PEMBAHASAN}

3.1 Implementasi Sistem

Implementasi sistem membahas mengenai sistem yang telah dibangun sesuai perancangan yang sudah di buat pada bab sebelumnya. Halaman Login di tunjukan pada Gambar 6. Pada Halam tersebut terdapat username dan password.

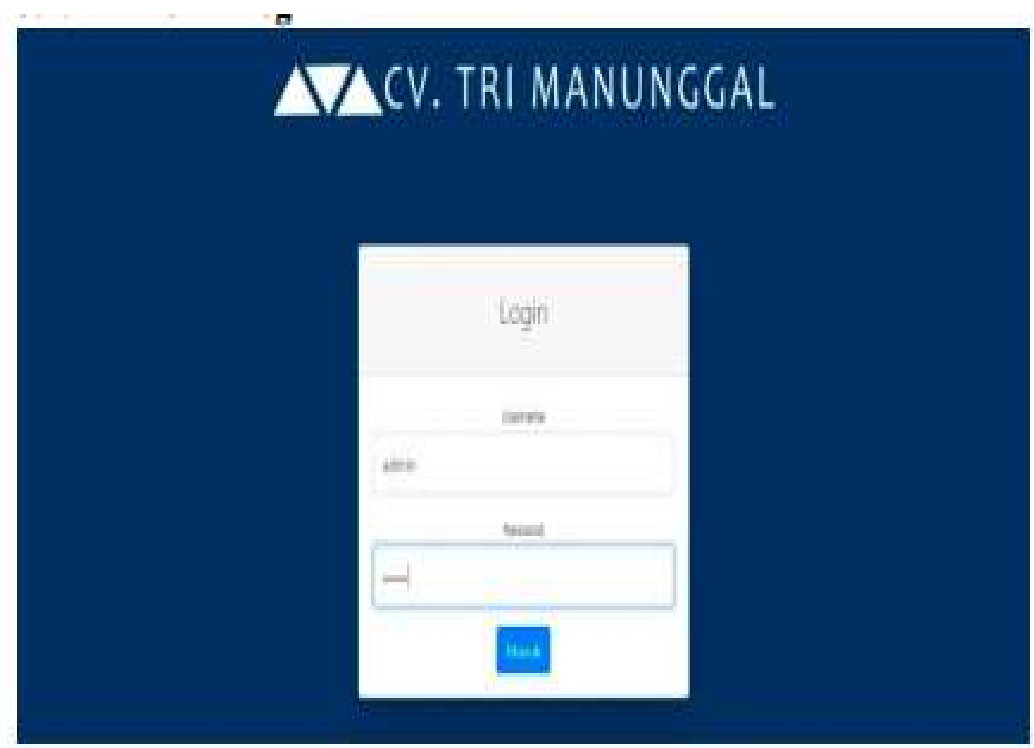

Gambar 6 Menu Login 
Pada halaman admin yang dapet diakses oleh admin, terdapat beberapa menu seperti data barang, persediaan barang barang dan pencatatan. Seperti ditunjukan pada Gambar 7, yang merupakan halaman admin.

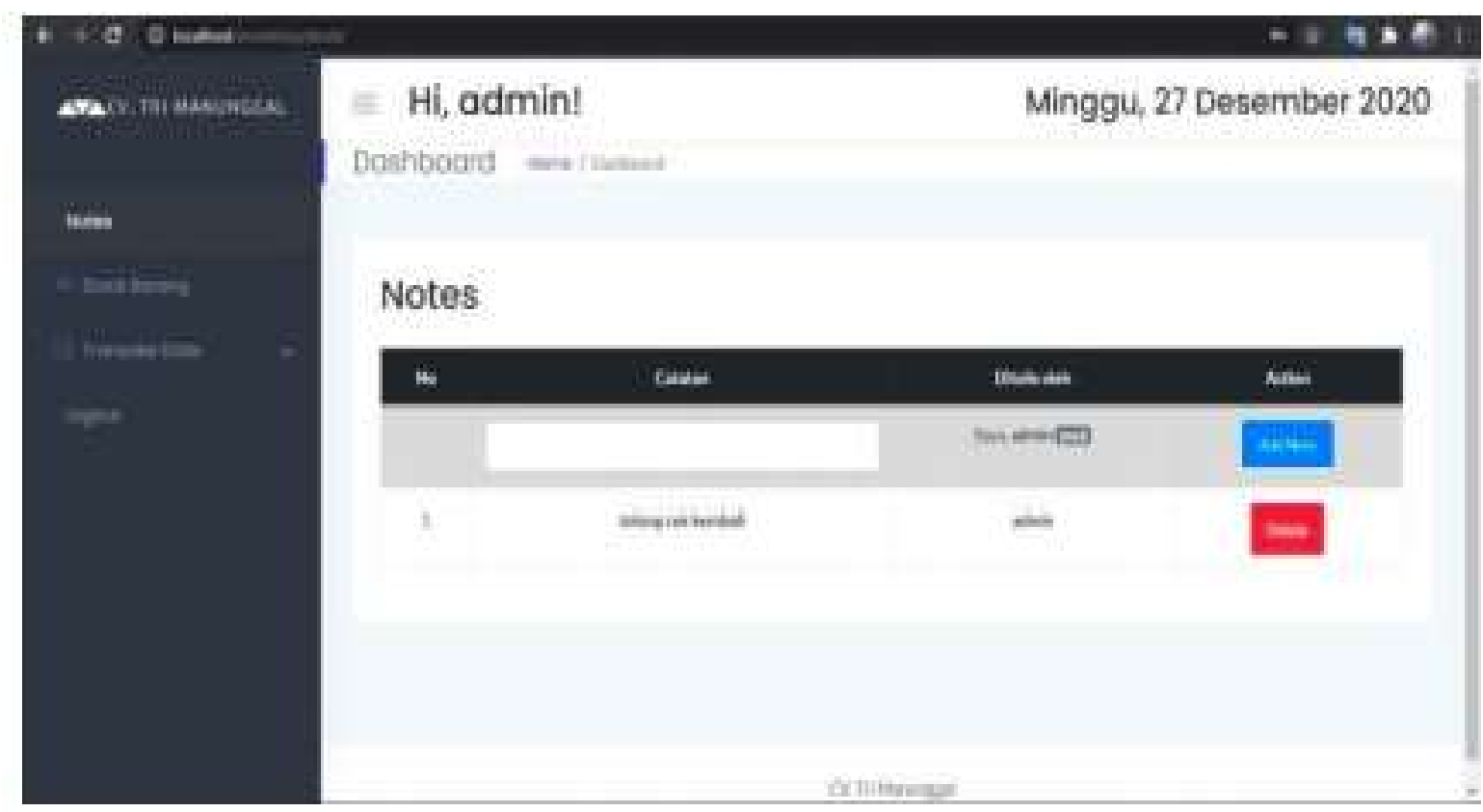

Gambar 7 Halaman Utama dan pencatatan

\subsection{Halaman Stok Barang dan Barang Masuk}

Pada Gambar 8 dan 9 menunjukan implenetasi terhadap data barang dan barang masuk. Pada halaman tersebut dapat diakases oleh admin, sedangkan user hanya dapat melihat data tersebut. Sedangkan pada Gambar 10 menunjukan Halaman barang keluar.

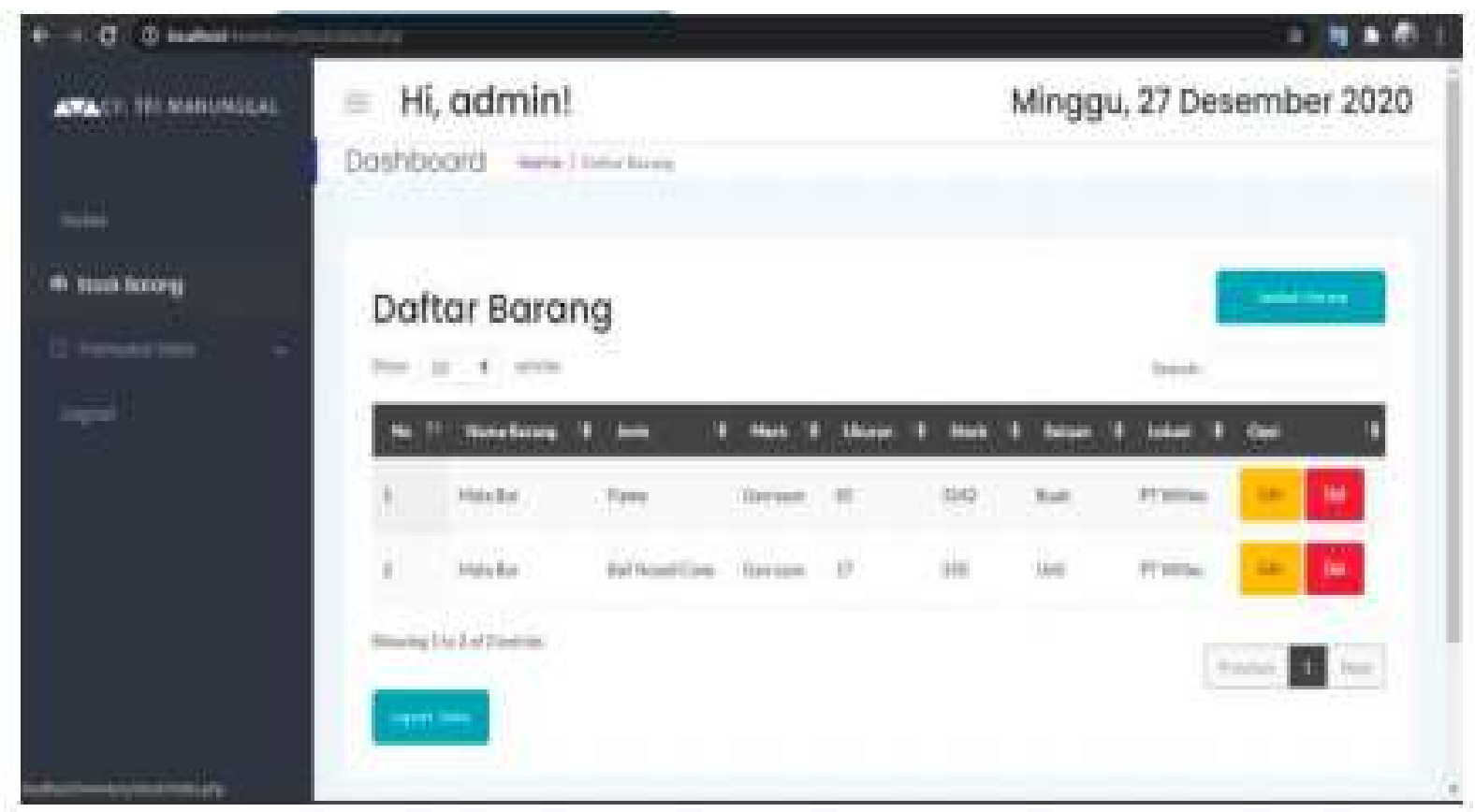

Gambar 8 Halaman Data Barang

JSIKTI Vol. 2, No. 3, Maret 2020: $14-25$ 


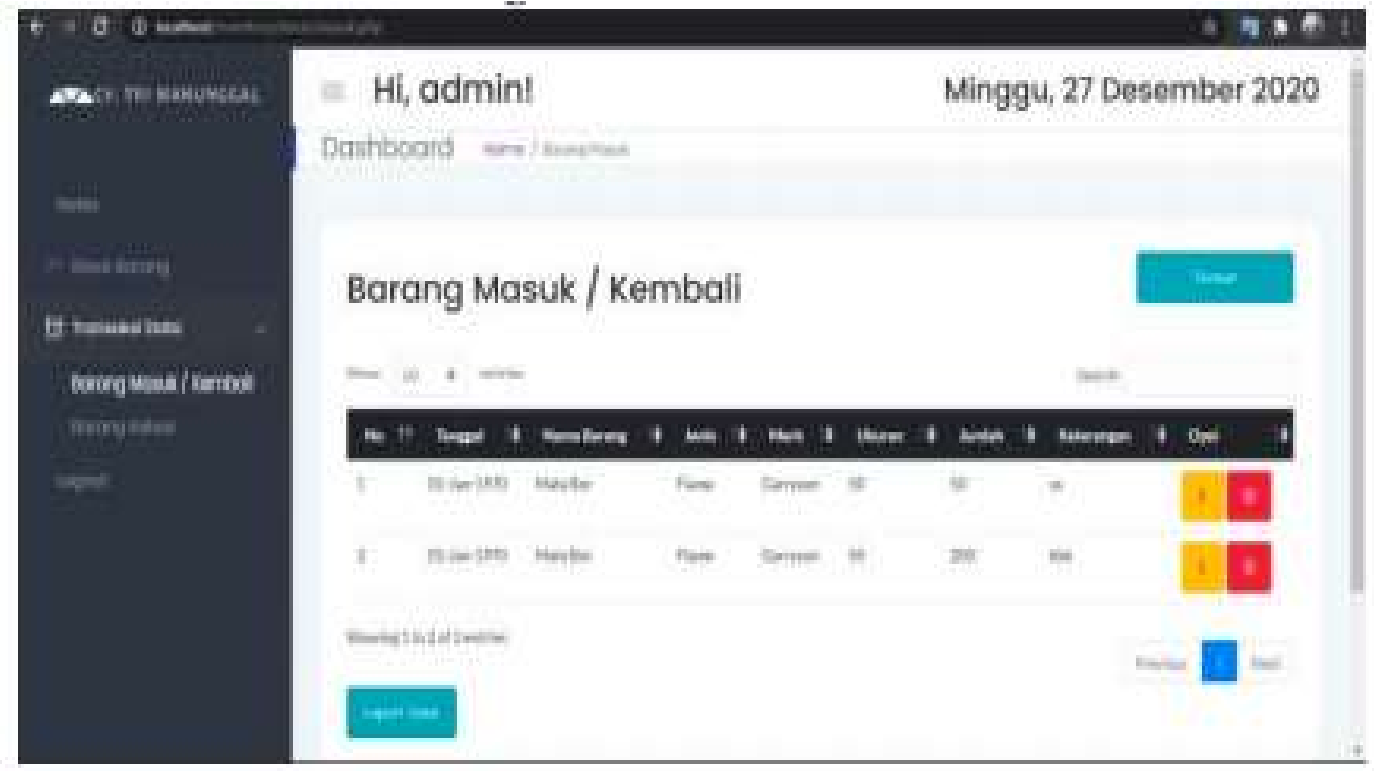

Gambar 9 Halaman Barang Masuk

Pada Gambar 9 Merupakan halaman untuk barang masuk, didalamnya terdapat detail dari barang masuk. Variabel barang meliputi no, tanggal, nama barang, jumlah, harga, ukuran, keterangan, dan kuantitas (qty)

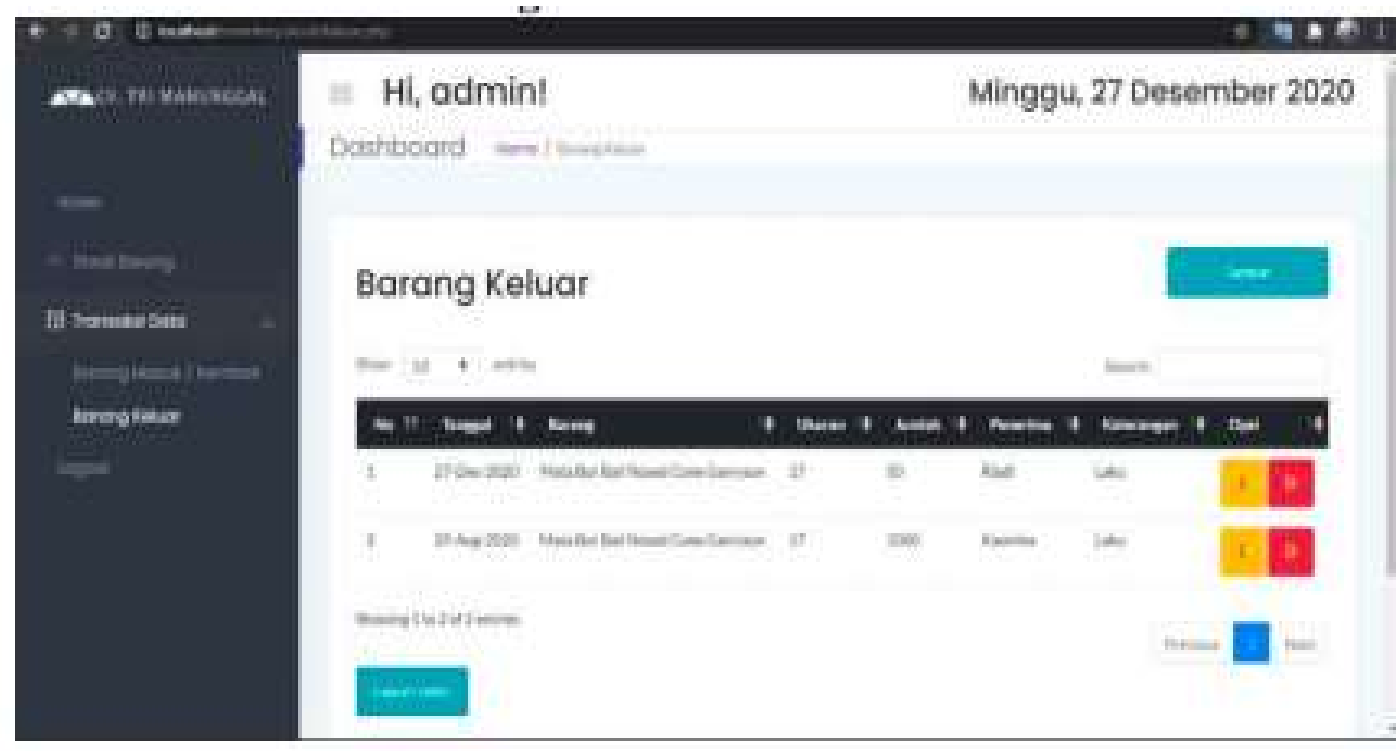

Gambar 10 Halaman Barang Keluar

Gambar 10 merupakan form untuk barang keluar. Adapun tampilan dari form tersebut memiliki kemiripan dengan form barang masuk.

\subsection{Pengujian Sistem}

Pengujian sistem dilakukan untuk mengamati hasil eksekusi melalui data uji dan memeriksa fungsi dari hasil pengujian sistem. Pengujian sistem menggunakan metode pengujian Black-Box Testing. Yang di tunjukan pada Tabel 1. 
Tabel 1 Pengujian Sistem Black-Box Testing

\begin{tabular}{|l|l|l|l|l|}
\hline No & $\begin{array}{l}\text { Aktifitas } \\
\text { Pengujian }\end{array}$ & Realisasi yang diharapkan & $\begin{array}{l}\text { Hasil } \\
\text { Pengujian }\end{array}$ & Kesimpulan \\
\hline 1 & $\begin{array}{l}\text { Masuk halaman } \\
\text { login }\end{array}$ & $\begin{array}{l}\text { Menampilkan halaman } \\
\text { login } \\
\text { yang dilakukan oleh } \\
\text { administrator dengan } \\
\text { memasukkan username } \\
\text { dan } \\
\text { password. }\end{array}$ & $\begin{array}{l}\text { Halaman } \\
\text { Login } \\
\text { berfungsi } \\
\text { sesuai harapan. }\end{array}$ & $\begin{array}{l}\text { [X] Diterima } \\
\text { [ ] Ditolak }\end{array}$ \\
\hline 2 & $\begin{array}{l}\text { Masuk ke } \\
\text { halaman utama } \\
\text { dan notes }\end{array}$ & $\begin{array}{l}\text { Menampilkan halaman } \\
\text { notes dan admin dapat } \\
\text { membuat notes pada tabel } \\
\text { notes. }\end{array}$ & $\begin{array}{l}\text { Halaman notes } \\
\text { berfungsi } \\
\text { sesuai harapan }\end{array}$ & $\begin{array}{l}\text { [X] Diterima } \\
\text { [ ] Ditolak }\end{array}$ \\
\hline 3 & $\begin{array}{l}\text { Masuk ke } \\
\text { halaman Barang } \\
\text { Masuk }\end{array}$ & $\begin{array}{l}\text { Admin dapat melihat data } \\
\text { barang masuk terkini dan } \\
\text { menambah data barang } \\
\text { masuk. }\end{array}$ & $\begin{array}{l}\text { Halaman } \\
\text { barang masuk } \\
\text { berfungsi } \\
\text { dengan baik. }\end{array}$ & [X] Diterima Ditolak \\
\hline 4 & $\begin{array}{l}\text { Masuk ke } \\
\text { halaman Barang } \\
\text { Keluar }\end{array}$ & $\begin{array}{l}\text { Admin dapat melihat data } \\
\text { barang keluar dan } \\
\text { menambah data barang } \\
\text { keluar }\end{array}$ & $\begin{array}{l}\text { Halaman } \\
\text { barang keluar } \\
\text { berfungsi } \\
\text { dengan baik. }\end{array}$ & $\begin{array}{l}\text { [X] Diterima } \\
\text { [ ] Ditolak }\end{array}$ \\
\hline 5 & $\begin{array}{l}\text { Memanfaatkan } \\
\text { fitur-fitur lainnya } \\
\text { seperti export } \\
\text { data }\end{array}$ & $\begin{array}{l}\text { Admin dapat melakukan } \\
\text { print out, copy, dan } \\
\text { mengubah format file } \\
\text { menjadi data excel, csv, } \\
\text { pdf. Tetapi harus } \\
\text { terkoneksi dengan jaringan } \\
\text { internet. }\end{array}$ & $\begin{array}{l}\text { Fitur Export } \\
\text { Data berfungsi } \\
\text { dengan baik }\end{array}$ & $\begin{array}{l}\text { [X] Diterima } \\
\text { [ ] Ditolak }\end{array}$ \\
\hline 6 & $\begin{array}{l}\text { Mdmin mengklik menu } \\
\text { logout dan otomatis sistem } \\
\text { akan logout }\end{array}$ & $\begin{array}{l}\text { Menu Logout } \\
\text { berfungsi } \\
\text { dengan baik. }\end{array}$ & $\begin{array}{l}\text { [X] Diterima } \\
\text { [ ] Ditolak }\end{array}$ \\
\hline
\end{tabular}

\section{KESIMPULAN}

Dari pembahasan mengenai sistem informasi inventori pada CV. Tri Manunggal berbasis web tentunya membantu staf di kantor perusahaan khususnya dalam pencatatan stok barang supaya lebih mudah dan efisien. Dapat diketahui bahwa sistem inventori ini merujuk kepada sistem pencatatan otomatis yang dilakukan oleh pengguna atau admin dalam memanajemenkan data.

\section{SARAN}

Bagian melihat perkembangan teknologi informasi yang semakin canggih, maka dapat disarankan agar fitur-fitur yang tersedia dikembangkan lagi atau ditambah fitur lainnya supaya memiliki nilai guna lebih. 


\section{DAFTAR PUSTAKA}

[1] H. Agusvianto, "Sistem Informasi Inventori Gudang Untuk Mengontrol Persediaan Barang Pada Gudang Studi Kasus: PT.Alaisys Sidoarjo," J. Inf. Eng. Educ. Technol., vol. 1, no. 1, p. 40, 2017, doi: 10.26740/jieet.v1n1.p40-46.

[2] R. S. Naibaho, "Peranan Dan Perencanaan Teknologi Informasi Dalam Perusahaan," J. War., no. April, p. 4, 2017, [Online]. Available: https://media.neliti.com/media/publications/290731-peranan-dan-perencanaan-teknologiinform-ad00d595.pdf.

[3] A. R. Anggraini and J. Oliver, "Journal of Chemical Information and Modeling," $J$. Chem. Inf. Model., vol. 53, no. 9, pp. 1689-1699, 2019.

[4] Y. Syafitri and E. Misgianti, "Membangun Sistem Informasi Persediaan Barang Dagang ( Studi Kasus : CV Sumber Sejahtera Bandar Lampung )," Jurnal Cendikia, vol. 14, no. 1. pp. 26-32, 2017.

[5] Fitri Ayu and Nia Permatasari, "perancangan sistem informasi pengolahan data PKL pada divisi humas PT pegadaian," $J$. Infra tech, vol. 2, no. 2, pp. 12-26, 2018, [Online]. Available: http://journal.amikmahaputra.ac.id/index.php/JIT/article/download/33/25.

[6] G. Rifai, I. W. Rai Widarta, and K. Ayu Nocianitri, "Pengaruh Jenis Pelarut Dan Rasio Bahan Dengan Pelarut Terhadap Kandungan Senyawa Fenolik Dan Aktivitas Antioksidan Ekstrak Biji Alpukat (Persea Americana Mill.)," J. Ilmu dan Teknol. Pangan, vol. 7, no. 2, p. 22, 2018, doi: 10.24843/itepa.2018.v07.i02.p03.

[7] M. Hasanudin, "Rancang Dan Bangun Sistem Informasi Inventori Barang Berbasis Web (Studi Kasus PT Nusantara Sejahtera Raya)," J. IKRA-ITH Inform., vol. 2, no. 3, pp. 24 37, 2018.

[8] F. Soufitri, "Perancangan Data Flow Diagram Untuk Sistem Informasi Sekolah (Studi Kasus Pada Smp Plus Terpadu)," Ready Star, vol. 2, no. 1, pp. 240-246, 2019.

[9] D. O. Sumadya, H. H. Ginardi, and R. J. Akbar, "Perancangan dan Implementasi Basis Data Aplikasi Web Fotokita," J. Tek. ITS, vol. 5, no. 2, pp. 2-5, 2016, doi: 10.12962/j23373539.v5i2.18771.

[10] D. C. P. Diaz, Sulistiowati, and J. Lemantara, "Rancang Bangun Aplikasi Penjualan Online Issn 2338-137X," Jsika, vol. 5, no. 12, pp. 1-7, 2016, [Online]. Available: https:/jurnal.stikom.edu/index.php/jsika/article/view/1480/900. 